\title{
Mercados de abasto y trabajadores. Negociaciones, disputas y formas de ganarse la vida en Buenos Aires, 1850-1870
}

\section{Valeria Silvina Pita}

Conicet - IIEGE

vspita@gmail.com

Title: Markets of supply and workers. Negotiations, disputes and ways to make a living in Buenos Aires, 1850-1870

Resumen: Este artículo busca examinar una serie de encuentros y desencuentros entre tenderos, trabajadores de los mercados de abastecimiento y agentes del municipio para vislumbrar algunas de las tensiones que surgieron ante la presencia de esa autoridad pública en los mercados. Al acompañar las demandas de los hombres y mujeres de los mercados es posible registrar experiencias laborales -con sus jerarquías, características y dinámicas- y algunas de las nociones sobre lo justo y los derechos que quienes las ejercian empleaban o recreaban ante las intervenciones municipales.

Palabras clave: trabajo - mercados de abasto - puestos - regulaciones municipales - derechos

\begin{abstract}
This article seeks to examine a series of encounters and disagreements between shopkeepers, workers of the markets of supply and agents of the municipality, in order to glimpse some of the tensions that emerged before the presence of public authority in the markets. It explores the demands of men and women in the markets, understanding that it is possible to record labor experiences -with their hierarchies, characteristics and dynamics- and some of the notions of fairness and rights that those who exercised them used or recreated before municipal interventions.
\end{abstract}

Keywords: work - market - stalls - municipal regulatios - rights

Recepción: 9 de enero de 2019. Aceptación: 1 de febrero de 2019.

(Archivos, año VII, no 14 , marzo de 2019, pp. 53-73) 


\section{Introducción}

En septiembre de 1868, el alemán Emilio Frings pidió a las autoridades de la Municipalidad de Buenos Aires que lo eximieran de abonar una multa por carecer de la patente correspondiente para el Café y Billar que había abierto a fines de agosto en el Mercado de Constitución. En la nota que presentó, declaró que había intentado cumplimentar los trámites en tiempo y forma, pero "como extranjero ignoraba" lo que debía hacer. ${ }^{1}$ Por ello, no había podido dar con los distintos funcionarios que tenían que sellar el permiso para la apertura de su comercio. Unos días después, su versión de los hechos fue confrontada por el encargado de inspeccionar los puestos del radio del mercado y por los municipales de la oficina de patentes, quienes desmintieron su declaración. Al ser interrogados, el inspector y el empleado de la oficina de patentes indicaron que el alemán había comenzado los trámites de patente de su comercio una vez que se le había intimado a hacerlo. ${ }^{2}$ No es posible saber cuál de las partes tenía razón. Mas entre ambas versiones es posible detectar el hilo de unas desavenencias que escondian acuerdos y desacuerdos cotidianos en un espacio, como el del mercado y sus alrededores, en el cual puesteros, comisarios, inspectores, agentes municipales, comerciantes y trabajadores se reconocerian al cruzarse e interactuar.

Un tiempo más tarde, Juan Lanza, un italiano que tenía una carnicería en una casilla de madera en la calle del Parque número 40, en las inmediaciones de otro mercado, denunció ante las autoridades municipales haber sido intimado por el comisario de policía de la sección $1^{\circ}$ para desalojar su local. Según expuso en su nota, desconocía si había una disposición municipal que lo obligara a cerrar su local, ya que "me ha ordenado el dicho comisario (a desalojar) en el corto término de tres dias". ${ }^{3}$ Desde el municipio debieron preguntar al comisario sobre dicha acción, ya que efectivamente no existía una razón municipal para ello. Ante lo que el comisario respondió que el desalojo había sido demandado por los puesteros del mercado que se hallaba en el radio y que veían afectados sus negocios por dicha carnicería.

La autonomía con la que actuaban algunos comisarios de policía,

1. "Nota al Sr. Presidente de la Municipalidad", 6 de septiembre de 1868, Archivo Histórico de la Ciudad de Buenos Aires (AHCBA), Fondo Corporación Municipal (FCM), Economía (E), Caja 4, 1868.

2. "Nota al Sr. Presidente de la Municipalidad", 14 de septiembre de 1868, AHCBA, FCM, E, Caja 4, 1868; “Nota al Sr. Presidente de la Municipalidad”, 22 de septiembre de 1868, AHCBA, FCM, E, Caja 4, 1868.

3. "Nota al Sr. Presidente de la Municipalidad", 24 de abril de 1869, AHCBA, FCM, E, Caja 5, 1869. 
sus arreglos con los puesteros y las tensiones que se libraban ante la ruptura de los acuerdos entre funcionarios policiales y agentes municipales tampoco eran excepciones en aquellos tiempos. Por el contrario, en las primeras décadas de la segunda mitad del siglo XIX, altercados y confrontaciones como los protagonizados por el alemán Frings o el italiano Lanza fueron corrientes en los mercados porteños y sus alrededores. Agentes municipales y hombres y mujeres que vivian de sus pequeños negocios en los mercados de la ciudad entraban en tensiones y negociaciones cotidianas. En los litigios sobre permisos y patentes, la disposición de los puestos, el estado de las mercaderías, el cumplimiento de los impuestos, las ventas y los intercambios permitidos y los no permitidos, es posible observar una diversidad de situaciones cotidianas que hacían a los mundos del trabajo y a las formas de relación entre trabajadores, comerciantes, habitués de los mercados y ciertos agentes municipales que buscaron regular esos espacios. Al acercar el foco a los mercados de abasto, estos sitios de uso y circulación colectiva, habilitados para realizar transacciones mercantiles, y apropiados y resignificados como ámbitos de encuentro y sociabilidad popular, es posible repensar algunas de las dimensiones de ese mundo del trabajo y de las relaciones sociales que ahi se gestaron.

Este artículo busca registrar algunas de las disputas y de las negociaciones cotidianas entabladas entre quienes arrendaban los puestos, trabajaban en ellos o concurrian a los mercados y quienes, desde el municipio porteño, intentaron regular las actividades que en esos espacios se generaban. Al dirigir la atención a las relaciones entre agentes públicos y aquellos y aquellas que laboraban, comerciaban, o circulaban en los mercados, es posible vislumbrar algunas de las tiranteces que hicieron a la presencia de autoridades públicas en esos sitios de múltiples usos. A su vez, al acompañar determinadas demandas pueden rastrearse los contornos de algunos de los significados sociales del trabajo, lo justo y los derechos empleados por hombres y mujeres ante las intervenciones municipales.

Entre la década de 1850 y la de 1870, funcionaron en Buenos Aires una decena de mercados. Sus edificaciones habian comenzado a planearse a finales de la década de 1850 y fueron inaugurándose formalmente en la de 1860. Se idearon como sitios de venta de productos de abasto, con locales y puestos diferenciados, jerarquizados según el sitio de ocupación en la edificación y el tamaño. La mayoría de ellos habian sido construidos por empresarios que labraron contratos con las autoridades municipales, en los cuales concentraban los locales en un sitio centralizado, abonaban anualmente un canon y respetaban ciertas injerencias públicas en materia de seguridad, higiene y patentes, entre otras. A cambio, el municipio garantizaba un radio libre de locales a 
la calle y de vendedores ambulantes, instituyendo de este modo a los mercados como sitios exclusivos de intercambio, compra y venta. Estas características no solamente hicieron de los mercados espacios para el comercio de abasto sino que los conformaron como instancias de permanentes idas y vueltas entre empresarios, puesteros, trabajadores, policías y municipales por la observancia de los contratos, las normativas vigentes, los saldos de impuestos y multas, la actualización de las patentes comerciales, la higiene, como así también por las tensiones y desencuentros que se generaban entre las personas que circulaban por esos mercados.

Entre los mercados más populosos estaban el de Lorea (1864), el de Independencia (1866), el de Florida (1866), el Del Centro (1862) el Del Plata, (1862), el Del Comercio (1862) y el de Constitución (1862). En su mayoria, estos mercados funcionaban en sitios que en el pasado habian sido plazas o antiguos mercados. Desde la inauguración o reapertura de los mercados edificados o consignados por un terreno y sus radios, empresarios, municipales, funcionarios, comerciantes, trabajadores, transeúntes, viajeros, personas de ciudad y de campo, se encontraron y desencontraron en ellos. Los espacios no siempre se organizaron de modo ordenado. Por el contrario, puestos, cuartos, casillas, tiendas y carretas se ubicaban caóticamente. Entre ellos circularon inspectores, porteros, dependientes y habitués que se abastecían en los mercados. Hubo en esos mercados personas que se ganaron la vida en la ciudad como el alemán Emilio Frings, quien decidió armar su negocio en el mercado de Constitución, en una casilla de madera con unas mesas y un billar usado. Pero también hubo otros trabajadores y trabajadoras que compraban, vendian, ofrecían emplear su tiempo en faenas ocasionales, dormian, comían y se entretenian en los mercados y sus cercanías.

La historiografia social ha reparado escasamente en los mercados y sus gentes en la ciudad de Buenos Aires para las primeras décadas de la segunda mitad del siglo XIX. Las preocupaciones de historiadores e historiadoras se centraron en explicar las dinámicas económicas y financieras que hicieron de Buenos Aires el principal centro mercantil de productos agropecuarios del país. Comerciantes y empresarios, así como las redes comerciales que se gestaron entre la campaña y la ciudad, fueron también tema de estudio entre distintos especialistas interesados en discernir cómo esas redes funcionaron ensanchando las posibilidades de un desarrollo capitalista en la región. Los estudios en torno a los mundos del trabajo acompañaron los interrogantes sobre la formación de una economía capitalista, revisitando la formación de un mercado de trabajo asalariado, libre y unificado. Los trabajadores de la ciudad y del campo, las maneras en que hombres de origen europeo se incorporaron a los mundos del trabajo bonaerenses y las caracte- 
rísticas que iba asumiendo un mercado de trabajo capitalista fueron los principales tópicos abordados por la historiografia del período. El empeño en estudiar la formación de un mercado de trabajo capitalista involucró describir quiénes y cuántos eran los trabajadores, reconocer cuáles fueron los vínculos que establecieron con ese mercado en proceso de conformación. No obstante, el peso analítico se inclinó más hacia los trabajadores varones vinculados a la economía agroexportadora. En tal sentido, al preguntar por otros hombres y mujeres que de una u otra manera llevaban sus vidas laborales en los mercados de la ciudad, es posible no solo entrever a las mujeres sino también reflexionar sobre las categorias empleadas, la elección de las evidencias y de los abordajes metodológicos. A la vez, al interrogar por las relaciones de trabajo y vida en los mercados de Buenos Aires puede repensarse en una escala más cercana la formación cotidiana de las relaciones capitalistas. Tales cuestionamientos forman parte de una investigación en curso y, aunque superan las posibilidades de este artículo, tenerlos en consideración guía el camino.

El artículo se divide en dos partes. En la primera, el alemán Frings del mercado de Constitución permite describir algunas de las características de ese mercado y sus gentes para percibir ciertas distinciones de quienes circulaban, transitaban, trabajaban o pernoctaban en ese mercado de las orillas. Reconocer algunas de sus características hace posible comenzar a reconocer unos mundos del trabajo poco explorados, los changarines, los hombres y mujeres observados como "vagos y mal entretenidos". En la segunda parte, el foco se desplaza a otros mercados porteños y sus radios, pone la atención en el mercado del Centro para reconocer algunos de sus conflictos cotidianos. Las tensiones entre inspectores, empresarios, dependientes de comercio y vendedores ambulantes invita a identificar conflictos y disputas, negociaciones y acuerdos entre quienes hacian de los mercados sus sitios de trabajo y estancia.

\section{En las orillas de la ciudad: el mercado de Constitución y sus gentes}

El café que abrió el alemán Emilio Frings en 1868, sin el permiso municipal, era una casilla de madera que constaba de unas mesas y un billar usado. Estaba ubicado sobre la calle Brasil, en el radio inmediato del mercado de Constitución. En esos años, se consideraba como parte del mercado a los puestos y casillas que se hallaban a una cierta distancia del mismo. Esta pertenencia implicaba obligaciones de permisos y pagos de patentes e impuestos municipales; como contraparte, se suponía que al estar ubicados en esos sitios los beneficios comerciales eran mayores. El mercado de Constitución, a diferencia de los otros que existian en la ciudad, no estaba estacionado en ninguna edificación 
centralizada. En realidad, no era más que un amplio asiento de tierra apisonada sin árboles ni otro tipo de vegetación. Había sido fundado por iniciativa de unos empresarios en unos terrenos municipales o municipalizados a comienzos de la década de 1860. Según constaba en los papeles, ocupaba el radio comprendido entre las calles Lima, Salta, Caseros y Cochabamba. Estaba estacionado en la zona sur de la ciudad, en un paraje cercano a los corrales de ganado, los mataderos y los saladeros de carne. Era un sitio que oficiaba como límite de la ciudad, lo que lo transformaba en una puerta de entrada y de salida de la misma. Para los contemporáneos, ese vértice sur, aunque apartado del casco urbano, no dejaba de estar vinculado al mismo. Cuando el alemán abrió su billar en 1868, hacía unos tres años que el Ferrocarril del Sur llevaba y traía hombres y acercaba granos y otros productos agropecuarios entre la localidad de Chascomús, a unos $100 \mathrm{~km}$. de la ciudad puerto, y la estación terminal también ubicada en el paraje. El tráfico y asiento de carretas era intenso y con el correr de los años siguió aumentando. Este movimiento constante de personas que ingresaban o salian por el ferrocarril, las carretas o caballos, así como su localización periférica, le dieron al mercado un perfil singular. En Constitución, los comerciantes ofrecian sus productos en casillas de madera, en tiendas de tela o desde sus carretas. Entre los intercambios que se declaraban oficialmente predominaban los vinculados a distintos cueros, principalmente vacunos, aunque también habia puestos que ofrecian de nutria y de venado. Otras tiendas mercadeaban garras, plumas, cerda, lanas, astas, grasas y cereales como trigo y maíz (Memoria, 1860: 58).

$\mathrm{El}$ ir y venir de personas y productos generaba no solo intercambios comerciales sino también otras transacciones y encuentros. El canto, los bailes o el juego habilitaban acuerdos entre varones y mujeres, traian la ciudad a las personas del campo y el campo a quienes habitaban en la ciudad. A inicios de los años 1860, los empresarios del mercado de Constitución observaron con preocupación a quienes circulaban y rodeaban el paraje. Declararon que en los alrededores de los terrenos delimitados para funcionar como mercado habia una

infinidad de rancheros que sin tendencia mercantil, ni elementos de negocio, no son sino otras tantas madrigueras de mujeres relajadas e inmundas, asilos de desertores y bandidos, foco de escándalos y robos. ${ }^{4}$

La estampa que delineaban esos hombres de negocios, que tenían

4. "Nota al Sr. Presidente de la Municipalidad", sin fecha, 1862, AHCBA, FCM, E, Caja 16, 1862. 
intereses económicos en juego y que buscaban generar una decisión a su favor de parte de las autoridades municipales, no sorprendía a sus contemporáneos. Municipales y otros agentes públicos, viajeros y observadores, periodistas, vecinos y moradores podian reconocer a simple vista que en ese extremo de la ciudad, como en otros parajes de Buenos Aires, podian encontrarse hombres y mujeres como los descritos por esos empresarios. ${ }^{5}$ Los rancheros de Constitución, que vivian en casillas de adobe, paja o madera, sobreviviendo de maneras diversas, a veces de lo que ganaban por unos dias de trabajo como peones, changarines, mandaderos en los mercados, en las tropas de carretas, en los corrales o los saladeros o las fincas cercanas, y otras veces de lo que robaban o hurtaban, eran parte del universo laboral varonil de una Buenos Aires popular. También lo eran las mujeres que vivian de la prostitución o que hacian de ella un trabajo alternado entre los trabajos de costura, las cocinas de las casas o fondas u otras ocupaciones que ingresaban en el ambiguo mundo del servicio doméstico.

Entre autoridades públicas y publicistas del liberalismo, estas mujeres y estos varones eran comúnmente identificados bajo la figura de "vagos y mal entretenidos". En esta denominación entraban no solo aquellos y aquellas que carecían de una ocupación estable sino también quienes no poseían papeles que acreditaran dirección, dependencia laboral o colocación. También incluía a los desertores del ejército o de las fronteras. La de "vagos y mal entretenidos" era además una figura de largo aliento, que había conformado una especie de hilo conductor de prácticas y discursos judiciales y policiales desde tiempos coloniales. Sin embargo, las concepciones, las nociones y los valores que se forjaron alrededor de la misma fueron mudando. Los vagos y mal entretenidos o las prostitutas, nombradas por estos hombres de negocios como "mujeres relajadas e inmundas", ponen el acento en una sanción moral. Mas en esa Buenos Aires popular, la sobrevivencia portaba inestabilidades y ambigüedades que se niegan tras las determinaciones morales de esos contemporáneos. En las primeras décadas de la segunda mitad del siglo XIX hubo mujeres que vivieron de la prostitución o de otros trabajos, del conchabo de ellas o de sus hijos, de otros tipos de ayuda o socorros, moviéndose de una forma de sobrevivencia, de un modo más suelto que el que los juicios de los empresarios dejarían registrar. Las experiencias laborales y de sobrevivencia de estas mujeres, que acompañaban a los rancheros, asentados en los terrenos públicos, a los changarines, que les preparaban comidas, que bailaban y dormían con quienes circulaban por sitios como el del mercado de Constitución, permiten renovar las

5. "Medidas Higiénicas", La Tribuna, 3 de marzo de 1871; "Es digno de aplausos", El Nacional, 2 de marzo de 1871. 
preguntas sobre los mundos del trabajo decimonónico, sobre la convivencia de distintas formas de contratación, de retribución, de valoración del trabajo y sobre la delimitación de lo que los y las contemporáneas entendian por trabajo.

Para esos empresarios, además, quienes paraban en esos terrenos aledaños carecian de algo que era apreciado por empleadores y empresarios, la disciplina laboral, lo que redundaria en una idea que fue cobrando fuerza con la instalación del régimen liberal en los años 1850 y que hacia de la figura de la vagancia un opuesto al trabajo. En la provincia de Buenos Aires esta asociación política fue acompañada por dispositivos legales que reprimieron diversas prácticas con el objetivo de reducir la autonomía de esos hombres y mujeres. ${ }^{6}$ Estas medidas recayeron principalmente sobre varones jóvenes, peones del interior que se trasladaban a Buenos Aires. Se los reclutó para los ejércitos, ya sea para continuar con las luchas armadas entre la provincia y el interior o para custodiar y avanzar sobre la frontera indígena. También las reglamentaciones disciplinarias facilitaron la satisfacción de las demandas del empresariado rural que requería de mano de obra para sus actividades. No obstante, no eran pocos los que se salían del servicio en las estancias o en los fortines de la frontera dirigiéndose a la ciudad, viviendo de un modo no tan lejano al que conocían de la campaña. Esos hombres vistos, por otros de la elite, como "desertores y bandidos", circulaban por los pasos de ingreso y salida de la ciudad, los terrenos baldíos y los mercados y sus alrededores, buscando changas, trabajos de ocasión, dineros a cambio de algunos productos que podían conseguir en la campaña próxima, u otros rebusques no siempre considerados dentro de la ley.

Unos años después de la nota de los empresarios de Constitución, el encargado municipal de la Comisión de Higiene de la parroquia de Monserrat, uno de los barrios más populosos de Buenos Aires, densamente poblado por afrodescendientes, demandaba la atención de las autoridades en un sentido semejante. El problema radicaba en un terreno baldío en el radio del mercado de Lorea. Según explicaba, en la esquina formada por Zeballos y Moreno había "un terreno baldío depositario de materias fecales e inmundicias de todo género y abrigo perpetuo de escandalosas escenas nocturnas". ${ }^{7}$ Reclamaba, entonces,

6. En este mismo dossier, ver un análisis de estas prácticas coactivas para disciplinar a la fuerza de trabajo en el artículo de Gabriel Di Meglio, Raúl Fradkin y Florencia Thul, así como una reflexión sobre los usos del concepto de "vagancia" en el trabajo de Sabina Dimarco.

7. "Nota al Sr. Presidente de la Municipalidad", 4 de agosto de 1871, AHCBA, FCM, Servicios Públicos (SP), Legajo 16, Caja 16 (73). 
la acción de las autoridades para limpiar el sitio y la de la policía para disuadir las reuniones.

Cerca del terreno denunciado había otro en condiciones similares. Los municipales denunciaron que en la esquina de la calle Entre Ríos y Belgrano existía "una casa en malas condiciones de aseo y en mal estado que es al mismo tiempo un foco de infección y una rinconada, que hace la misma casa". ${ }^{8}$ A comienzos de los años 1870 , las rinconadas hacian referencia a terrenos vacíos o sin dueños conocidos, y a la par a las reuniones nocturnas que ahí se daban. Los habitués de las rinconadas eran mayoritariamente hombres, cuyos trabajos u ocupaciones los acercaban a esas zonas. Conductores de carretas, peones y cargadores de bultos o bolsas, changarines de ocasión, se movian por los radios del mercado, muchas veces iban armados y se trasladaban en sus propios caballos. ${ }^{9}$ Cuando llegaba la noche preparaban un fogón y alrededor de éste comian, bebian, cantaban y jugaban, lo que resultaba ser una forma de convivencia y encuentro colectivo que despertaba alarma entre municipales, inspectores, vecinos notables o empleadores.

Al volver al mercado de Constitución y a sus alrededores a finales de los años 60, es posible reconocer que el universo de personas que ahí circulaban no distaba demasiado de las denunciadas por los empresarios unos años antes. En el verano de 1871, la seccional policial del lugar había detenido y remitido al Departamento Central de Policía a un grupo de varones, quienes eran definidos por el escribiente de la policia en los términos siguientes:

Todos ellos pertenecen a lo que se conoce con el nombre de vago y mal entretenido, y cada uno ha tenido repetidas entradas en nuestras cárceles, sin que las correcciones que han sufrido hayan sido eficaces para modificar sus actitudes. Y todos estos arrestados carecen de ocupación, y viven en las casas de prostitución, jugando y estafando y cometiendo materias de delitos cuando se les presenta la oportunidad. ${ }^{10}$

La asociación entre vagos, prostitución, juego, delito, hombres sin ocupación seguía presente y habilitaba en este caso al comisario de

8. "Nota al Sr. Presidente de la Municipalidad", 10 de octubre de 1871, AHCBA, FCM, SP, Legajo 11.

9. Archivo General de la Nación (AGN), Archivo Intermedio, Policía de la Capital, año 1868-1871, Número 3, División Central, sección 14, Copiador de notas desde el 4 de noviembre hasta el 7 de enero, Libro 65, caja 11, 1871, F: 285 y F: 297.

10. AGN, Archivo Intermedio, Policía de la Capital, año 1870-1871, Jefatura, C. de Órdenes, Notas al Gobierno 1 de abril a 21 de mayo, 1871, papel suelto entre los folios 176 y 177. 
la seccional a suponer que tenía la prerrogativa de apresarlos sin que hubieran cometido contravención alguna salvo la de carecer de papeles, buscando -como lo declaró- que el Tribunal de Justicia les aplicara el código rural que permitía hacerlos cumplir servicios obligatorios. Sin embargo, el crecimiento del mercado y la radicación de nuevos y más trabajadores también en su radio otorgó al sitio una impronta más matizada, la que a la par podría indicarnos la heterogeneidad del mundo de los trabajadores y trabajadoras vinculados a este mercado.

Al observar la cuadra del Café y Billar del alemán Frings, es posible registrar algo de esto. Sobre la calle Brasil, al lado del café, había una casa de cuartos de alquiler donde, según se declaró en el censo de población de 1869, se alojaban peones, dependientes, changadores, cuidadores de caballos, cocheros y sirvientas. También en la misma cuadra había un corralón para animales, un puesto de comidas y otros dedicados al pequeño comercio. ${ }^{11}$ En esa parcela las edificaciones eran de madera, adobe y paja. Oficialmente, se contaron unas 24 familias, censándose a unas setenta y seis personas de origenes nacionales variados entre los que habia italianos, franceses, alemanes, ingleses y también locales, aunque no eran parte de la mayoria. ${ }^{12}$ Frings, como otros de sus vecinos comerciantes, vivía en su local. En su misma cuadra, el italiano Gandolfi, que se declaró tendero, lo hacía con su familia, que era numerosa. En Constitución, aunque rápidamente se habian construido casillas que funcionaban con distintos fines, no era nítida la distinción entre lugares de trabajo, dormitorio, alimentación y diversión. La indiferenciación de espacios no era algo que sucediera sólo en la zona de este mercado. Por el contrario, se podría considerar que era una de las características cardinales de los hábitats populares en la ciudad de Buenos.

Casillas, billares, carretas, ferrocarriles, bailes, naipes, changarines, mujeres relajadas, vagos y mal entretenidos formaban parte de un sitio y un escenario popular en el cual trabajo, dormitorio, entretenimiento y comercio se combinaban de un modo poco comprensible para autoridades públicas y patrones. Sus presencias permiten divisar los contornos de unos mundos del trabajo en los cuales hombres de campo y de ciudad no estaban tan separados como se los ha colocado en los estudios del trabajo. Tampoco son tan evidentes las diferencias entre sitios de trabajo y de estancia, entretenimiento o dormitorio, invitando a consi-

11. Fichas censales del Censo Nacional de 1869. Disponible en linea en FamilySearch. org, FHL microfilm 677,648.

12. Fichas censales del Censo Nacional de 1869. Disponible en linea en FamilySearch. org, FHL microfilm 873,901. 
derar con mayor detenimiento las posibles combinaciones entre trabajo y sociabilidades populares en espacios públicos y de circulación masiva.

\section{En el centro de la ciudad: de los negocios de los mercados y sus conflictos}

A partir de la década de 1860, los mercados comenzaron a ser objeto de negocios empresariales que buscaron convertirlos en los principales centros mercantiles de la ciudad. En 1862, los miembros de la Municipalidad reforzarian dicha política al prohibir mercados de abasto en las plazas. La resolución de los municipales obligaba en los papeles a concentrar la venta y la compra de productos en ciertos sitios supervisados, prohibiendo las ferias y mercaditos desregulados o no controlados por alguna empresa. Municipales y administradores argumentaron que los mercados centralizados formaban parte de un proyecto urbano, que implicaba erigir edificios, iluminar las calles, volver a diagramar los paseos y plazas públicas, lo que también implicaba desplazar pretéritas formas de reunión y encuentro popular. En 1856, un redactor del periódico El Nacional, cuando se inauguró el mercado del Plata en lo que era la Plaza de las Artes, celebró su apertura al entender que la edificación de mercados, con los consecuentes desplazamientos de feriantes y vendedores ambulantes, era una muestra del grado de "la civilización de los pueblos". ${ }^{13}$

Probablemente, quienes vivian de los intercambios comerciales a distintas escalas que se daban en la antigua plaza no pensaran de manera afin al redactor. Tampoco coincidirian con los supuestos beneficios económicos que traería rentar un puesto en el mercado, ya que desde entonces deberian abonar un alquiler a los administradores del mercado, como también impuestos y gravámenes diversos a la Municipalidad y a la Provincia. A pesar de las intenciones políticas, la creación de nuevos mercados no impidió que estos funcionaran como centros de encuentro y convivencia popular. Las epidemias y brotes de cólera, fiebre amarilla, tifus y viruela hicieron que hombres de prensa, inspectores y politicos municipales, policias, médicos y hombres de la elite produjeran una gran masa de escritos de denuncia y alarma ante las superposiciones de funciones en ellos.

En la actual Plaza de Mayo, los puestos de la llamada Recova Vieja, un edificio alargado y con arcos que había sido inaugurado a fines de la colonia, eran motivo constante de quejas. Allí se vendían telas, lanas, artículos de bazar, cueros. Pero también se podian hallar en sus extremos tiendas de carnes y verduras. Varios dias a la semana, las carretas llegaban con productos del campo y los puestos en el piso se

13. "Mercado del Plata", El Nacional, 3 de octubre de 1856. 
multiplicaban. Desde antaño, las negras vendian golosinas y comidas al paso, patas de vaca, empanadas, mazamorras, huevos, refugiándose cuando llovía en medio de los puestos de la Recova (Wilde, 1922: 13). La aglomeración de personas, los fuertes olores que se desprendian de los puestos, las pequeñas habitaciones en los altos y altillos generaban la voz de alarma en tiempos de epidemia y los pedidos de clausura y expulsión de sus habitués o moradores.

A menos de diez años de su inauguración, el mercado del Plata también fue foco de denuncias. En medio de la epidemia de fiebre amarilla de 1871, un redactor del periódico La República lo definió como "ratoneras [...], donde se ocultan toda especie de podredumbres y verdaderos focos de infección". ${ }^{14}$ Denunciaba a quienes ahí se alojaban, entendiendo que la profusión de cuartitos y altillos que hacian de dormitorio en su interior eran ámbitos privilegiados para el contagio. Otra crónica afirmaba que "sin mucho esfuerzo se nos ofrece el espectáculo del sucio colchón, de las más sucias almohadas y frazadas del abastecedor" que dormía en el mercado, como también "los zapatones, las medias, los escarpines, los pantalones"15 de aquellos otros que pernoctaban ahí.

Los municipales ordenaron a "sus dueños u ocupantes a deshacer los altillos construidos sobre puestos de los mercados", ${ }^{16}$ justificando su decisión en la existencia de normativas que indicaban que debía mediar un espacio mínimo de cuatro varas de alto en los techos, lo que no sucedía con frecuencia a causa de que los altillos se construían con menos altura para aprovechar el espacio.

La policía fue la encargada de supervisar la demolición de altillos y los desalojos en los mercados. Algunos comisarios mandaron a publicar que habian llevado adelante las tareas encomendadas. Este fue el caso de quien actuó en los mercados del Plata y de Lorea, que avisó que habian sido desocupados "todos los puestos establecidos en el suelo de las calles y las mesas situadas en el cuadro interior" ${ }^{17} \mathrm{El}$ funcionario que intervino en el mercado de la parroquia de Catedral al Sur también informó haber cumplido con la orden. Dejó asentado y mandó a publicitar que durante dos dias seguidos se había presentado a las dos de la mañana "a efecto de dar las disposiciones necesarias para la mejor dirección en la descarga y acomodamiento de las verduras y remover los puestos ambulantes" que no cumplieran con las disposiciones del momento. ${ }^{18}$

14. La República, 8 de marzo de 1871.

15. La República, 4 de marzo de 1871.

16. La República, 6 de marzo de 1871.

17. La República, 6 y 7 de marzo de 1871.

18. "Nota al Sr. Presidente de la Corporación Municipal", 6 de marzo de 1871, AHCBA, FCM, SP, Caja 14, 1871. 
Unas semanas después, reaparecieron las denuncias sobre los dormitorios y albergues en los mercados. Así lo hizo saber el mismo presidente de la Comisión de Higiene de Catedral al sur al Presidente Municipal, cuando anunció la resolución de no asistir a partir de la fecha "a ninguna persona atacada de la epidemia en las habitaciones y fondines que se encuentran indebidamente en el interior del mercado, así como en los fondines de las inmediaciones". Acompañó la medida con otra, la del cierre de "los bodegones y almacenes de bebidas que se hallan también en el interior del mismo". La decisión intentaba inhabilitar esos pequeños dormitorios y el ir y venir de gentes en el mercado. La aglomeración de personas en los mercados dejaba en claro que estos funcionaban, para hombres y mujeres del mundo popular, como sitios donde pernoctar, trabajar y también entretenerse. El billar de Frings no era el único que estaba habilitado en el radio del mercado de Constitución y menos aún era el único sitio donde se jugaba. Los hombres del municipio, los mismos que denunciaban la presencia de vagos y mal entretenidos, no dudaban en habilitar licencias para este tipo de locales. Las autoridades públicas habian prohibido hacía décadas las corridas de toros y las riñas de gallos. Sin embargo, habian alentado la lotería, los naipes y la quiniela al convertirlos en una fuente de recaudación, pues se vendian licencias, se organizaban loterias y se recaudaban impuestos. El juego en los mercados, con sus sitios habilitados, se habría transformado en una instancia de negociación y de tensión, en la cual podian confluir hombres del municipio, encarnados en recaudadores e inspectores, policias, trabajadores y prostitutas, entre tantas otras gentes que se movian en aquellos.

En los mercados de la ciudad, las relaciones entre los hombres del municipio y quienes tenían sus puestos en estos no eran sencillas. La creación de los mercados había significado exclusiones, corrimientos y nuevas demandas para quienes comerciaban, sobre todo para los más pobres o sin capital. La reapertura del mercado del Centro en 1862 y las exigencias que estableció la Municipalidad nos permiten acercarnos a la situación que debieron afrontar a partir de ese momento quienes se dedicaban a vender distintos productos en escalas muy disimiles. Reconocer estas situaciones hace accesible saber algo del mundo del pequeño comercio y de sus hombres y mujeres.

El mercado del Centro había sido edificado en la manzana comprendida entre las calles Perú, Chacabuco, Adolfo Alsina y Moreno. La construcción tenía una planta alta y una planta baja, diferenciadas además en tres tipos de locales: puestos, cuartos y casillas. Tales distinciones, que involucraban en cada caso un tipo de construcción, una cantidad de metros cuadrados, ubicaciones centrales o periféricas dentro del mercado, podrian indicar una variedad de posibilidades para quienes 
accedieran a rentarlo y por lo tanto la existencia también de fuertes distinciones y jerarquías entre aquellas y aquellos que se dedicaban a vender para vivir. En efecto, los puestos diferian entre los de primera, de segunda y de tercera clase. Los de primera eran aquellos que daban a las concurridas calles Chacabuco y Alsina, los que daban hacia la calle Moreno, donde se encontraba la Comisaria de la Parroquia, todos los que estaban ubicados en las esquinas del edificio y los que tenían mostrador. Desde su reacondicionamiento, todos estos puestos debian pagar por ser de primera clase, además de un alquiler mensual, un canon extra que se contabilizaba por la cantidad de varas de frente que tuvieran. Para el año 1863, la tasa se estableció para los de primera clase en 2 pesos por vara, y para los de segunda y los de tercera clase en 1 peso por vara. Simultáneamente, los alquileres estaban gravados de modo diferencial según el tamaño, el sitio en el mercado y el rubro al que se dedicaran los locales. Las rentas más onerosas eran las de los cuartos bajos dedicados a la chanchería, cuyo alquiler ascendía -según los papeles- a unos 1.200 pesos. Le seguian los que estaban estacionados en las entradas, esquinas o en sus cercanías; por ejemplo, los cuartos bajos que llevaban el número 1 y 2 y que estaban en la entrada principal del mercado abonaban unos 200 pesos mensuales y los puestos cercanos abonaban unos 150 pesos mensuales. No obstante, si el puesto era de fruta o carne, aunque no tuviese una ubicación central podía llegar a abonar unos 300 o 250 pesos, según su asiento. Los cuartos se abonaban entre 200 pesos si eran bajos y entre 100 pesos y 50 pesos si estaban en los altos. A su vez, se distinguían una serie de rubros: cuartos o puestos de carne, de carne y de pescado, chanchería, de diferentes abastos, de carnero y cordero, de fruta y de verdura. ${ }^{19}$

Quienes estaban comerciando adentro del mercado no eran los únicos que tenían exigencias de abonar aranceles. La instalación de un radio y la consideración de que este estaba compuesto también por las calles y plazas exteriores al mismo implicó nuevos gravámenes para quienes trabajaban vendiendo en carretas, carros, mantas o canastas. Aquellas personas que, desde una carreta, ofertaran por las calles artículos de mercado, abonarian una suma por día. También lo harian aquellos vendedores o vendedoras que circularan a pie por las manzanas del radio.

Se sabe poco sobre cómo se hacía efectivo el pago de alquileres e impuestos y cuáles eran las posibilidades de los vendedores más pobres de escapar a la supervisión de autoridades públicas y a los recaudadores de impuestos de los empresarios. La municipalidad solía publicar en sus balances el monto de lo recaudado en impuestos y multas y el

19. "Contrato con Don Carlos Urien sobre el derecho del Mercado del Centro y Plaza exteriores", en Memoria (1863: 118-122). 
cumplimiento de los contratos con los empresarios. Si los empresarios abonaban el canon acordado se puede suponer que esto significaba que habían cobrado los alquileres y los dineros de las otras obligaciones a los hombres y mujeres del mercado. En enero de 1869, salió a la luz el conflicto suscitado desde el año anterior, cuando los vendedores ambulantes del radio del mercado del Centro se negaron a pagar el llamado derecho de sisa a la empresa que administraba el mercado. Tal evento trae algunos indicios acerca de cómo esos hombres y mujeres, que vivian de la venta callejera, se comportaron ante la presión recaudatoria de los empresarios. Según quedó registrado, se habían rehusado a pagar desde agosto del año anterior, presentándose además ante el "Gobierno pretendiendo se les exonerase del referido pago". Por algún motivo, las autoridades municipales dieron la orden de no hacer intervenir a la Policía de la ciudad. Solicitaron a los alcaldes y auxiliares del mercado, quienes dependian del municipio, buscar la manera de cobrar el impuesto. Medio año después, los empresarios todavia aguardaban recibir esos dineros. Reclamaron nuevamente la acción del municipio a su favor, "suplicando se sirva determinar su autoridad que ha de hacer efectivo el pago, imponiéndoles a los contraventores la correspondiente multa como la tienen establecida los vendedores ambulantes". ${ }^{20}$

A inicios de 1869, el pedido de los empresarios ponía de relieve una dificultad concreta, la de cobrar a los vendedores ambulantes que circulaban por el radio del mercado del Centro, quienes de alguna manera se habian reunido para no abonar. Por otra parte, la decisión de las autoridades municipales de no hacer intervenir a los oficiales de policía abre interrogantes acerca de sus posibilidades para convocar a aquella fuerza en aquel momento. Pero, a la par, esa medida permite preguntar por el tipo de relaciones que podian darse entre ciertos empleados municipales y los vendedores y vendedoras ambulantes, y por los acuerdos y negociaciones que formarian parte de aquellas. Alcaldes de los cuarteles, auxiliares e inspectores del municipio formaban parte de la dinámica cotidiana de los mercados. Estos empleados que compartirian el espacio, que recorrian los mercados de vez en cuando, que estaban en ocasiones domiciliados en sus cercanias y que tenian relaciones con algunas autoridades públicas, podrían en distintas oportunidades habilitar o trabar sus negocios y trabajos. Este fue el caso del alemán Emilio Frings, quien en una de las notas para evitar pagar la multa por su falta de licencia invocó que había mantenido contacto

20. "Nota al Sr. Presidente de la Municipalidad, Empresa del Mercado del Centro", 26 de enero de 1869, AHCBA, FCM, E, Caja 3, 1869. 
con "el Alcalde Don José Rey", a quien le había hecho "presente que iba a abrir un Billar en el Mercado de Constitución". ${ }^{21}$

El municipio no recaudaba directamente aquellos gravámenes diarios o mensuales que habilitarian a los vendedores y vendedoras ambulantes a trabajar en los radios de los mercados. Los llamados inspectores de mercados (uno para el norte de la ciudad y otro para el sur) eran los encargados de inspeccionar y supervisar los negocios y vendedores de los mercados, sus radios y demás comercios. Las condiciones laborales no siempre parecian ser las mejores para estos hombres. En 1869, uno de los inspectores que había sido recientemente nombrado reclamó al Presidente del Municipio que subvencionara la manutención de un caballo. Dejó asentado que le era "indispensable para recorrer el inmenso radio que abraza la sección a mi cargo", que comprendía a los mercados del Centro, Comercio, Independencia y los pueblos de la Boca, Barracas y San Antonio. Basaba su pedido no solo en la inmensa área que debía recorrer para detectar locales y puestos sin licencia, intimar y multar a los infractores, sino también en

la exigüidad del sueldo que disfruto con relación a la tarea personal, pues excede en muchas horas de trabajo a cualquier otro destino, me impelen a solicitar la referida subvención sin la que no me es posible dar debido cumplimiento a mis deberes sin el sacrificio de una parte de mi sueldo. ${ }^{22}$

Este hombre, que declaraba necesitar de una subvención para mantener a su caballo, era uno de los encargados de supervisar a los negocios y vendedores del radio de los mercados. Es dificil suponer que el inspector pudiera moverse por su cuenta y sin el auxilio de un animal. En esa ciudad transitar por sus calles a pie no era fácil, no solo por las distancias que debian cubrirse sino porque con las lluvias dichas calles se anegaban, mientras que los arroyos desbordaban y los pantanos se ensanchaban. En ocasiones, este inspector debía informar su imposibilidad para llegar a ciertos lugares. En octubre de 1869, advertía a la municipalidad que "el mal estado de algunas calles no me ha permitido llegar a algunos puestos distantes". ${ }^{23} \mathrm{Al}$ seguir los pasos de este hombre a lo largo de ese año, se puede reconocer que tenía una presencia más

21. "Nota al Sr. Presidente de la Municipalidad", 6 de septiembre de 1868, AHCBA, FCM, E, Caja 4, 1868.

22. "Nota al Sr. Presidente de la Municipalidad, Inspector de Mercados al Sud", 3 de septiembre de 1869, AHCBA, FCM, E, Caja 3, 1869.

23. "Nota al Sr. Presidente de la Municipalidad, Inspector de Mercados al Sud", 8 de octubre de 1869, AHCBA, FCM, E, Caja 3, 1869. 
constante en ciertos momentos y en determinados sitios, en especial en los de mayor aglomeración mercantil como el mercado del Centro y sus alrededores, el de Independencia y el de Constitución. Esto no habría pasado desapercibido para otros municipales. Así lo hicieron saber los miembros de la Comisión de Higiene de la parroquia de San Miguel cuando denunciaron el mal estado del mercado del Plata, que debía quedar bajo su vigilancia. En la denuncia presentada afirmaban: "La Comisión pues cree que el actual Inspector del Mercado del Plata, el cual nunca inspecciona ni pasa en él, debería removerse de su empleo". ${ }^{24}$

A pesar de las críticas de esos municipales, el inspector en cuestión tenía una cierta presencia en la vida cotidiana y laboral de vendedores, puesteros, comerciantes y otros trabajadores de los mercados de la zona sur de la ciudad. Podía multar sus actividades, convocar a la fuerza pública, hacer tirar la fruta que considerara verde o podrida o determinar la remoción de sus puestos, entre otras acciones. Los italianos Juan Vianchessi, Domingo Girandelli y Rafael Folio, puesteros de los exteriores del mercado de Constitución, entre otros, lo sabrian. En una de las visitas semanales al mercado los había apercibido con una multa de 100 pesos por infracciones al reglamento. ${ }^{25}$ La cifra era significativa para unos carniceros con puestos menores y ubicados en lugares periféricos del radio del mercado. Un tiempo antes Santiago Cires, quien también trabajaba de carnicero en un local de la Boca del Riachuelo, fue multado "por no tener su puesto de carnes como prescribe el reglamento". ${ }^{26}$ Durante ese año 1869, este mismo inspector revisaria puestos y casillas en los radios más concurridos de los mercados que le estaban adjudicados y cobraría en persona multas por distintas infracciones.

En junio de ese mismo año, el mismo inspector fue el encargado de notificar a los puesteros y vendedores del radio acordado entre la $\mathrm{Mu}-$ nicipalidad y los empresarios del mercado Independencia que debian desalojar los locales, pues en el contrato establecido no se permitía su permanencia. Según la resolución municipal se otorgaban tres meses para desalojar todos los locales cuyos rubros compitieran con los del mercado que se establecería. Dejó constancia de que entre las calles había notificado a 69 puesteros sobre el plazo y las razones de los desalojos. Sin embargo, no todos los puesteros acataron la decisión municipal. A fines de agosto, cuando ya el plazo estaba cumplido, el inspector buscó

24. "Nota al Presidente de la Municipalidad, Comisión de Higiene de la Parroquia de San Miguel", 2 de abril de 1869, AHCBA, FCM, E, Caja 3, 1869.

25. "Nota al Presidente de la Municipalidad, Inspector de los Mercados al Sud", 10 de septiembre de 1869, AHCBA, FCM, E, Caja 3, 1869.

26. "Nota al Presidente de la Municipalidad, Inspector de los Mercados al Sud", 20 de mayo de 1869, AHCBA, FCM, E, Caja 3, 1869. 
labrar un acta sobre aquellos locales y puestos que seguían abiertos en el radio. Según informó, el encargado de uno ubicado sobre la calle Chile al 300 "se negó a oír", aunque había sido comunicado junto con el resto de los puesteros. Al tiempo que estaba preparando el acta que quería hacerle firmar "apareció una mujer profiriéndose en el lenguaje más impropio e insolente contra la municipalidad, atropellándome hasta fuera del umbral del puesto". El inspector requirió entonces "el auxilio del comisario de la sexta sección" para que le hiciera comparecer y le aplicase la multa que le correspondía "por escándalos e injurias, y que en caso de reincidencia de tales improperios, lo remitiese al departamento de Policía". ${ }^{27}$

Unas semanas después, una situación semejante sobrevino en la calle Santiago del Estero 185, cuando otro puestero se negó a firmar la notificación sobre la obligatoriedad de cierre de su puesto. El inspector dejó asentado que "no quiso dar su nombre", asociando su actitud a lo ocurrido en el puesto de la calle Chile, "donde el dependiente y la mujer produjeron un escándalo que fue preciso contener con el auxilio de la fuerza pública". Ese día, en su informe detalló que "muchos de los notificados [se habian] expresado en términos poco dignos", y que además le habían manifestado "la resolución de no trasladar sus puestos fuera del radio señalado". ${ }^{28}$ Pedía autorización a las autoridades municipales para convocar a la fuerza pública para que interviniese a fin de cerrar los puestos que se negaban a hacerlo hasta la fecha.

La creación de un radio para este mercado generó rechazo y resistencias entre aquellos y aquellas que tenian puestos sobre las calles. Entre ellos los había como Juan Lemerique, en cuyo local trabajaba un dependiente y su mujer, quien no tuvo empacho en sacar al inspector a empujones. Pero también había otros que sólo contaban consigo mismos para vender. Había quienes eran propietarios y otros que alquilaban. La mayoría vivía en los altillos o en la parte trasera de los locales. De tal manera que la clausura de sus negocios involucraría no solo tener que salir a buscar otro local u otra manera de arreglarse para vivir, sino también un sitio para hacer de dormitorio. Tales cuestiones dieron marcha además a quejas formales. Distintos puesteros escribieron o hicieron escribir notas a la Municipalidad para denunciar lo injusto de la decisión que los dejaba sin trabajo o en la calle.

Otros argumentaron basándose en lo que entendían era el marco legal más contundente que tenían a su disposición: la Constitución Nacional.

27. "Nota al Presidente de la Municipalidad, Inspector de los Mercados al Sud", 31 de agosto de 1869, AHCBA, FCM, E, Caja 3, 1869.

28. "Nota al Presidente de la Municipalidad, Inspector de los Mercados al Sud", 13 de septiembre de 1869, AHCBA, FCM, E, Caja 3, 1869. 
En base a lo que interpretaban de su contenido, algunos puesteros desmintieron las órdenes municipales, al entender que la municipalidad no tenía autoridad para mandar a clausurar sus negocios y cerrar sus trabajos. El inspector de los mercados del Sud dejó constancia de esto. Según escribió eran los extranjeros, además, quienes "han concentrado el más decidido empeño en contrariarla", dándoles "una interpretación errónea a nuestras leyes, creen que la municipalidad carece del poder de reglamentar" sobre la materia. Aclaraba además que había tenido que estar presente y oír:

discusiones que me han sido tan indecorosas, Señor que me han sostenido estas nuevas ilustraciones, interpretando nuestra Constitución y nuestras leyes, que por impropias, no las digo. No obstante, pretenden traernos la Civilización, los que en su mayor parte i aun saben leer.

Las palabras del inspector dejarian entrever la sorpresa e irritación que le generaba que las apelaciones impugnatorias sobre la potestad de la municipalidad fueran hechas en base a comentarios amparados en leyes y los derechos que estas garantizarian. El uso de la ley para defenderse de autoridades, personas o grupos con poder no era una novedad. Por el contrario, hombres y mujeres sin derechos legales, o con limitados derechos, o excluidos de los marcos legales, en distintos tiempos y lugares, apelaron a ella para defenderse, para demandar o reclamar ante lo que consideraban atropellos o injusticias. En 1869, no obstante, el uso de la ley como escudo por parte de sujetos no alfabetizados, no pertenecientes a la elite ni acaudalados, así como también extranjeros, llamó poderosamente la atención del funcionario. Estos hombres y mujeres objetaron las facultades que se atribuia la municipalidad. Así, cuando se ordenaba inspeccionar o clausurar un puesto, se lo hacia avasallando el derecho constitucional a la inviolabilidad del domicilio y dejando sin efecto las garantías a la libertad de trabajo y de comercio.

\section{A modo de cierre}

Este artículo se propuso reconocer algunas de las características de los mercados de la ciudad de Buenos Aires en sus primeros años de existencia. Intentó delinear ciertos rasgos físicos de algunos de ellos. En particular, del mercado de Constitución y del mercado del Centro. Dicha descripción permitió ubicar dónde estaban localizados y cómo estaban delimitados o edificados. Aspiró a la par a registrar algunas de las disputas y de los tratos cotidianos entre aquellos y aquellas que 
arrendaban puestos, trabajaban en estos o circulaban por los mercados, y quienes desde el municipio trataron de llevar adelante la regulación de los mismos y de las actividades que ahí se forjaban. Al señalar algunas de las relaciones gestadas entre municipales y hombres y mujeres vinculados a los mercados, hizo perceptible los alcances y límites de las intervenciones de las autoridades públicas en el área de aquellos.

También se registraron las formas en que ciertos trabajos eran considerados por empresarios y posibles patrones y más precisamente cómo ciertos hombres y mujeres eran definidos moralmente y no por sus trabajos, siendo los que llevaban, traían y vendian las mercaderías $\mathrm{u}$ ofrecian sus servicios en los mercados. Al detectar a esa franja de trabajadores definidos como "vagos y mal entretenidos", "mujeres de vida relajada e inmunda" se intentó traer también al mundo del trabajo a esos hombres y mujeres en ocasiones desplazados del mismo por la historiografia. Simultáneamente, al traer a un primer plano ciertas tensiones y conflictos entre inspectores, agentes públicos y trabajadores, fue posible reconocer que entre carniceros, mondongueros, encargados de cafés, vendedores de frutas o mazamorreras, nacidos o nacidas en el país o en el extranjero, circulaba por entonces un lenguaje de derechos, que invita a considerar cómo esos espacios de trabajo -los mercados y sus radios, con sus áreas de uso y circulación colectiva- fueron sitios de intercambios no solo mercantiles sino también culturales y políticos.

\section{Referencias}

Allemandi, Cecilia (2012), "El servicio doméstico en el marco de las transformaciones de la ciudad de Buenos Aires, 1869-1914", Diálogos, vol. $16, \mathrm{n}^{\circ} 2$, pp. 385-415.

Cecchi, Ana (2009), "Policía y juego: formas de legalidad en la ciudad de Buenos Aires (1890-1902)", en Ernesto Bohoslavsky, Lila Caimari y Cristiana Schettini (eds.), La policía en perspectiva histórica. Argentina y Brasil (del siglo XIX a la actualidad), Buenos Aires, CD-ROM.

Lobato, Mirta Zaida (2007), Historia de las trabajadoras en Argentina (18691960), Buenos Aires: Edhasa.

Memoria de la Municipalidad de la Ciudad de Buenos Aires correspondiente al año 1859 (1860), Buenos Aires: Imprenta del Orden.

Memoria de la Municipalidad de la Ciudad de Buenos Aires correspondiente al año 1862 (1863), Buenos Aires: Bertheim.

Mitidieri, Gabriela (2017), Costureras, modistas, sastres y aprendices. Una aproximación al circuito de trabajo de la costura. Buenos Aires, 18521862, Tesis de Licenciatura en Historia, Facultad de Filosofia y Letras, Universidad de Buenos Aires.

Pita, Valeria Silvina (2016), "Historia social del trabajo en perspectiva de género en Argentina: aspectos de un entramado en construcción", en S. 
Pérez Toledo y S. Paolo Solano (coords.), Pensar la historia del trabajo y de los trabajadores en América, siglos XVIII y XIX, Madrid-Frankfurt: Iberoamericana-Vervuert, pp. 183-201.

- (2017), "El género de la historia del trabajo: lecturas y dilemas situados. Buenos Aires, segunda mitad del siglo XIX", en S. Bandieri y S. Fernández (coords.), La historia argentina en perspectiva local y regional. Nuevas miradas para viejos problemas, Buenos Aires: Teseo, tomo 3, pp. 255-270. Sábato, Hilda y Luis Alberto Romero (1992), Los trabajadores de Buenos Aires. La experiencia del mercado: 1850-1880, Buenos Aires: Sudamericana.

Vial Moreira, Luis (2005), Las experiencias de vida en el mundo del trabajo: los sectores populares del interior argentino (Córdoba, 1861-1914), Córdoba: Centro de Estudios Históricos "Profesor Carlos S.A. Segreti".

Wilde, José Antonio (1922), Buenos Aires, desde setenta años atrás, Buenos Aires: Ediciones de la Luz. 